\title{
СОВЕРШЕНСТВОВАНИЕ ТЕХНОЛОГИИ ДОБЫЧИ НЕФТИ В УСЛОВИЯХ ИНТЕНСИВНОГО ВЫНОСА МЕХАНИЧЕСКИХ ПРИМЕСЕЙ
}

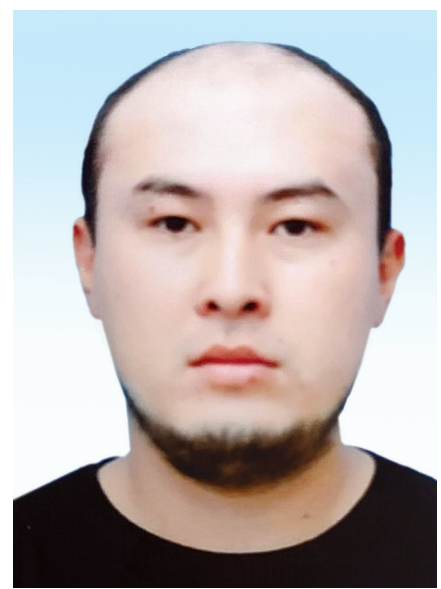

Д.Ж. БАЗАРБАЕВ, магистрант, https://orcid.org/0000-00020647-5002

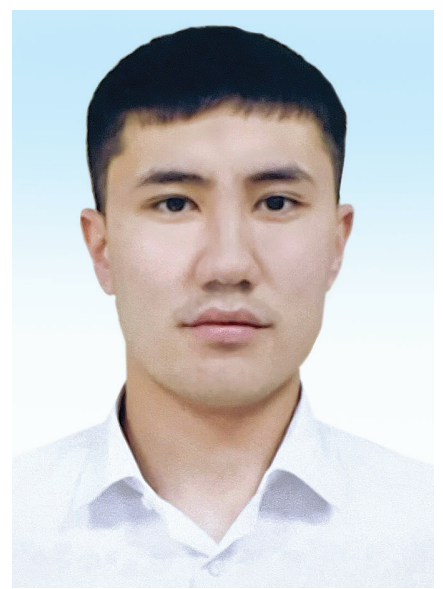

E.C. НУРMАШЕВ*, магистрант, https://orcid.org/0000-00026601-1066

АКТЮБИНСКИЙ РЕГИОНАЛЬНЫЙ УНИВЕРСИТЕТ ИМ. ЖУБАНОВА, Республика Казахстан, 030000, г. Актобе, проспект Алии Молдагуловой, 34

Важнейшей научно-технической проблемой разработки месторождений является одновременное обеспечение высоких уровней и темпов добычи углеводородного сырья при наиболее полном извлечении его из недр с высокими технико-экономическими показателями работы нефртегазодобывающих предприятий. Одной из причин, не позволяющей эффрективно решить эту проблему, является пескопроявление и вынос мехпримесей при эксплуатации скважин. И для совершенствования технологии добычи нефти можно использовать разные виды излучения. В данной работе обзорно представлены эти технологии.

Актуальностью работы является совершенствование технологии при добыче нефтти на примере Кенкиякского местрождения.

Результаты показывают, что залежи подсолевой части месторождения Кенкияк относятся к залежам с аномально-высоким давлением, их нефрть - слаболетучая.

КЛЮЧЕВЫЕ СЛОВА: месторождение, нефтедобыча, подводное оборудование, фракционный состав.

\footnotetext{
* Адрес для переписки. E-mail: balgyn.ashim@mail.ru
} 


\section{КЕНҚИЯҚ КЕН ОРНЫ МЫСАЛЫНДА МЕХАНИКАЛЫҚ ҚОСПАЛАРДЫ ҚАРҚЫНДЫ ШЫҒАРУ ЖАҒДАЙЫНДА МҰНАЙ ӨНДІРУ ТЕХНОЛОГИЯСЫН ЖЕТІЛДІРУ}

Б.Ж. БАЗАРБАЕВ, Жұбанов атындағы Ақтөбе өңірлік университетінің магистранты, https://orcid. org/0000-0002-0647-5002

E.C. НУРМАШЕВ*, Жұбанов атындағы Ақтөбе өңірлік университетінің магистранты, https://orcid. org/0000-0002-6601-1066

Қ. ЖҰБАНОВ АТЫНДАҒЫ АҚТӨБЕ ӨНІРЛІК УНИВЕРСИТЕТІ,

Қазақстан Республикасы, 030000, Ақтөбе қаласы, Молдағұлова даңғылы, 34

Кен орындарын игерудің маңызды ғылыми-техникалық проблемасы мұнай-газ өндіруші кәсіпорындар жұмысының техникалық-экономикалық көрсеткіштері жоғары жер қойнауынан неғұрлым толық алынған кезде көмірсутек шикізатын өндірудің жоғары деңгейі мен қарқынын бір мезгілде қамтамасыз ету болып табылады. Бұл мәселені тиімді шешуге мүмкіндік бермейтін себептердің бірі-ұңғымаларды пайдалану кезінде құмның пайда болуы және механикалық қоспаларды алып тастау. Мұнай өндіру технологиясын жетілдіру үшін сәулеленудің әртүрлі түрлерін қолдануға болады. Бұл жұмыс осы технологияларды шолумен ұсынылған.

Жұмыстың өзектілігі-Кеңқияқ кен орны мысалында мұнай өндіру технологиясын жетілдіру.

Нәтижелер Кеңқияқ кен орнының тұз астындағы кен орындары өте жоғары қысымды кен орындарына жататынын,олардың мұнайы нашар ұшатындығын көрсетеді.

TYЙІн СөзДЕР: кен орны, мұнай өндіру, суасты жабдықтары, фрракциялық құрам.

\section{IMPROVEMENT OF OIL PRODUCTION TECHNOLOGY IN CONDITIONS OF INTENSIVE REMOVAL OF MECHANICAL IMPURITIES ON THE EXAMPLE OF THE KENKIYAK FIELD}

D.ZH. BAZARBAYEV, Master's degree student of Zhubanov Aktobe Regional University, https:// orcid.org/0000-0002-0647-5002

E.S. NURMASHEV*, Master's degree student of Zhubanov Aktobe Regional University, https://orcid. org/0000-0002-6601-1066

K. ZHUBANOV AKTOBE REGIONAL UNIVERSITY, 34, A. Moldagulova Avenue, 030000, Aktobe, Republic of Kazakhstan

The most important scientific and technical problem of field development is the simultaneous provision of high levels and rates of production of hydrocarbon raw materials with the most complete extraction from the subsurface with high technical and economic performance of oil and gas production enterprises. One of the reasons that does not allow to effectively solve this problem is the sand occurrence and removal of mechanical impurities during the operation of wells. To improve the technology of oil production, different types of radiation can be used. This paper provides an overview of these technologies.

The relevance of the work is the improvement of technology in oil production on the example of the Kenkiyak deposit.

The results show that the deposits of the subsalt part of the Kenkiyak field belong to the deposits with abnormally high pressure, their oil is non-volatile.

KEY WORDS: field, oil production, underwater equipment, fractional composition.

есторождение Кенкияк было открыто в 1959 г., введено в эксплутацию в 1968 г., расположено в центральной части Жаркамысско-Енбекской зоны нефтегазонакопления. Температура пласта $20^{\circ} \mathrm{C}$ газовый фактор 4,6 м³/т, 


\section{РАБОТЫ МОЛОДЫХ УЧЕНЫХ}

плотность нефти в пластовых условиях 0,909 г/см³, средняя вязкость 145 сП. Надсолевые нефти в основном смолистые и малосернистые. Плотность нефтей при переходе от юрских к нижнетриасовым горизонтам изменяется от 0,917 до 0,813. «Кенкиякнефть» было проведено определение фракционного состава нефти (по Энглеру), в результате чего получены следующие данные:

Таблица 1 - Фракционный состав нефти

\begin{tabular}{|c|c|c|c|}
\hline $\begin{array}{c}\text { Температура } \\
\text { отгона, }{ }^{\circ} \mathbf{C}\end{array}$ & $\begin{array}{c}\text { Кол-во отогнанной } \\
\text { нефти, } \%\end{array}$ & $\begin{array}{c}\text { Температура } \\
\text { отгона, }{ }^{\circ} \mathbf{C}\end{array}$ & $\begin{array}{c}\text { Кол-во отогнанной } \\
\text { нефти, } \%\end{array}$ \\
\hline Н.к. $-130^{\circ} \mathrm{C}$ & 1,5 & 260 & 10,0 \\
\hline 180 & - & 270 & - \\
\hline 190 & 2,53 & 280 & 14,5 \\
\hline 200 & - & 290 & 21,5 \\
\hline 210 & 4,0 & 300 & 22,5 \\
\hline 220 & - & Общий выход & 77,5 \\
\hline 230 & 7,0 & Остатка и потер, $\%$ & \\
\hline 240 & - & & \\
\hline 250 & & &
\end{tabular}

Месторождение Кенкияк по своему построению - сложное: значительные тектонические нарушения, высокая степень неоднородности коллектора по толщине и простиранию, плохая выдержанность нефтенасыщенных пластов, их выклинивание, что в отдельных зонах затрудняет реализацию технологии паротеплового процесса с непрерывным нагнетанием теплоносителя.

Подсолевые отложения месторождения Кенкияк образуют два продуктивных горизонта: нижнепермский и каменноугольный. Нижнепермская нефтяная залежь является литологически экранированной (линзовидные), не имеет единого ВНК, а каменноугольная залежь - единой массивной, с ВНК на отметке - 4230 м утвержденные остаточные геологические запасы нефти нижнепермской залежи по категории C1 составляют 34013 тыс.т, по категории С2 - 40998 тыс.т, извлекаемые запасы соответственно по категории С1 - 5328 тыс.т, по категории С2 - 6477 тыс.т.

Утвержденные остаточные геологические запасы нефти по категории С1 каменноугольной залежи составляют 77163 тыс.т, извлекаемые запасы по категории С2 - 23139 тыс.т.

Всего извлекаемых запасов подсолевых залежей по категории С1 - 28467 тыс.т, за вычетом добычи нефти на дату утверждения запасов (173 тыс.т).

Суммарные геологические запасы нефти по всей подсолевой части месторождения составляют 152174 тыс.т, из них запасы нефти С1 - 111176 тыс.т.

По конфигурации структура подсолевых отложений представляется структурным «носом», с углом наклона к северо-западу. По кровле пласта КТ-П структура разбита нарушениями и состоит из нескольких куполов. По кровле нежнепермского горизонта данная структура менее разбита нарушениями.

Условием осадконакопления карбонатных пород-коллекторов каменноугольных отложений является мелководная морская область карбонатной платформы. В фациальном отношении данные породы-коллектора принадлежат к фации краевой платформенной части открытого моря и ее склона. А породы-коллектора нижне- 


\section{РАБОТЫ МОЛОДЫХ УЧЕНЫХ}

пермских отложений относятся к подводной дельте в переходных условиях осадконакопления, от континентального к морскому, дельта имеет веерообразную форму.

По литологическому составу породы-коллектора каменноугольных отложений в основном состоят из детритовых известняков. Тип коллекторов порово-кавернозный, поровая текстура в основном микроканальная, ее максимальный радиус менее 1 мкм, данные коллектора более или менее неоднородные. По разрезу коллектора имеют неоднородные свойства, среднее значение пористости $-8,74 \%$, среднее

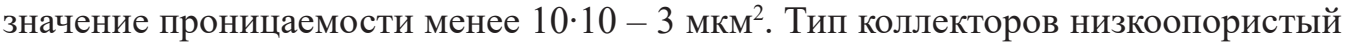
и низкопроницаемый.

В литологическом отношении породы-коллектора нижнепермских отложений представлены аркозовыми песчаниками и алевролитами. Коллекторы кавернозно-поровые, очень неоднородные и относятся к низкопоровым и малопроницаемым, среднее значение пористости - 8,74\%, среднее значение проницаемости - менее 10·10-3 мкм². Тип коллекторов - низкопористый и низкопроницаемый.

В литологическом отношении породы-коллектора нижнепермских отложений представлены аркозовыми песчаниками и алевролитами. Коллекторы кавернозно-поровые, очень неоднородные и относятся к низкопоровым и малопроницаемым, среднее значение пористости - около $10,7 \%$, среднее значение проницаемости 10·10-3 мкм².

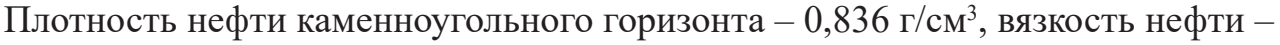
11,9 мПа-с $\left(20^{\circ} \mathrm{C}\right)$, содержание серы - 0,54\%, содержание смол - 23,3\%, газовый фактор 277,5 м³/ м $^{3}$. Плотность нефти нижнепермского горизонта - 0,842\%, вязкость нефти - $18 \mathrm{MПа-с}\left(20^{\circ} \mathrm{C}\right)$, содержание серы - 0,38\%, содержание смол - 21\%, газовый фактор 267,5 м³ м $^{3}$. В растворенном газе каменноугольной залежи содержание сероводорода $-1,6 \%$, а в нижнепермской залежи сероводород отсутствует.

Залежи подсолевой части месторождения Кенкияк относятся к залежам с аномально-высоким давлением, их нефть - слаболетучая. Коэффициент аномальности

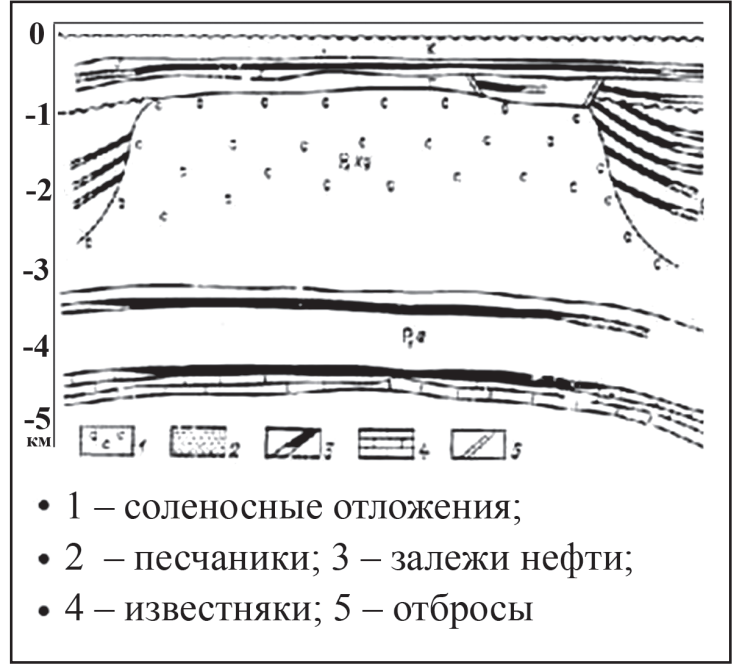

Рисунок 1 - Геологический разрез местрождения Кенкияк давления (отношения пластового давления к гидродинамическому на одной глубине) для каменноугольной залежи - 1,84, для нижнепермской - 1,79. Разница между пластовым давлением и давлением насыщения большая, соответственно, 47,5 и 45,3 МПа. Залежи обладают большим запасом естественной энергии.

На изучении естественной радиоактивности горных пород основан гамма-каротаж (ГК) или гамма-метод (ГМ). Это аналог радиометрии [2].

Работы проводят с помощью скважинных радиометров разных 
марок. Электрические сигналы, пропорциональные интенсивности гамма-излучения, передаются с них по кабелю в обычную каротажную станцию, где и осуществляется их автоматическая регистрация.

В результате гамма-каротажа записывается непрерывная кривая, или диаграмма интенсивности гамма-излучения. Величина измеряется в импульсах за минуту или в микрорентгенах в час (гаммах). Поскольку распад ядер является случайным процессом, то интенсивность гамма-излучения колеблется около среднего уровня, испытывая статистические флуктуации. Для их учета применяются повторные записи с меньшей скоростью проведения наблюдений. Так как гамма-лучи почти полностью поглощаются слоем породы толщиной 1-2 м, а до 30\% ядерной энергии не пропускается обсадными трубами, то скважинный радиометр может фиксировать гамма-излучение пород, расположенных в радиусе, не превышающем 0,5 м от оси скважины. Увеличение диаметра скважины и наличие воды или бурового раствора в ней еще больше снижают радиус обследования.

Спектрометрия естественного гамма-излучения, то есть определение энергии гамма-лучей служит для выделения в разрезах скважин пород и руд, содержащих определенные элементы, например, калий, торий, уран, фосфор и др. [2].

Гамма-каротаж (ГК) основан на измерении естественной гамма-активности горных пород. Самопроизвольный распад атомных ядер в естественных условиях (проявление радиоактивности) сопровождается альфа-, бета- и гамма-излучением. Все виды этих излучений, попадая в материальную среду, в той или иной мере испытывают поглощение. Наибольшему ослаблению подвержены $\alpha$-лучи, обладающие большой ионизирующей способностью. Поток $\alpha$-лучей почти полностью поглощается даже листом бумаги и слоем пород толщиной в несколько микрометров [1].

Поток $\beta$-лучей обладает большей проникающей способностью и полностью поглощается слоем алюминия толщиной до 8 мм или слоем породы в несколько миллиметров. Гамма-излучение представляет собой высокочастотное коротковолновое электромагнитное излучение, граничащее с жестким рентгеновским излучением с энергией, измеряемой в мегаэлектронвольтах (МэВ). (В системе СИ энергия измеряется в джоулях. 1 МэВ =1,6021·10-13 Дж.) Оно возникает в результате ядерных процессов и рассматривается как поток дискретных частиц $\gamma$-квантов. Благодаря своей высокой проникающей способности, гамма-излучение имеет практическое значение при исследовании разрезов скважин ( $\gamma$-лучи полностью поглощаются лишь слоем пород толщиной около $1 \mathrm{~m}$ ); наличие обсадной колонны не является препятствием для проведения измерений.

В строении УВ сорбированной части нефти намечается некоторое увеличение количества нафтеновых и ароматических колец. Состав поровой сорбированной части нефти отличается от исходной ( месторождение Кенкияк) и тем более от ее фильтратов резким повышением количества смолисто-асфальтеновых компонентов (соответственно 17 5; 119 и 9 5\%); количество парафино-нафтеновой фракции снижается до 17\% против 81 6\% в исходной нефти и 89\% в ее фильтрате. Поровая нефть, т.е. нефть, вытесненная водой, в основном сохраняет состав поровой сорбированной нефти [4].

Данный метод был использован при контроле за процессом нагнетания пара на месторождении Кенкияк. На его основании было установлено, что фронт 


\section{РАБОТЫ МОЛОДЫХ УЧЕНЫХ}

закачки в течение 2-х лет к югу не распространялся, основное направление было северным.

Свойство пород пропускать жидкости или газы через систему взаимосообщающихся пор называется проницаемостью.

Таким образом, анализы месторождения Кенкияк показали, что коэффициент проницаемости пород зависит от коэффициента пористости, характера, формы пор, размера зерен и поверхности порового пространства. Оценить величину коэффициента проницаемости можно по данным исследования скважин методами естественных потенциалов, сопротивлений и вызванной поляризации с использованием материалов анализа керна, по которым определяется литология пройденных скважиной пластов и размер зерен. Для разных типов пород имеются свои эмпирические зависимости коэффициента проницаемости от геофизических параметров.

\section{ЛИТЕРАТУРА}

1 Ахметов С. А., Ишмияров М. Х., Кауфман А. А. Технология переработки нефти, газа и твердых горючих ископаемых. - М.: Недра, 2009. - 844 с. [Akhmetov S. A., Ishmiyarov M. Kh., Kaufman A. A. Technologia pererabotki nefti, gaza i tverdyh goruchih iskopaemyh. - M.: Nedra, 2009. - 844 p.]

2 Иванов А. Н., Рапацкая Л. А., Буглов Н. А., Тонких М. Е. Нефтегазоносные комплексы.- М.: Высшая школа, 2009. - 232 с. [Ivanov A. N., Rapatskaya L. A., Buglov N. A., Tonkikh M. E. Neftegazonosnye kompleksy; - M.: Vysshaya shkola, 2009. - 232 s.]

3 Карнаухов М. Л., Пьянкова Е. М. Современные методы гидродинамических исследований скважин. - М.: Инфра-Инженерия, 2010. - 432 с [Karnaukhov M. L., Pyankova E. M. Sovremennye metody gidrodinamicheskih issledovanii skvazhin. - M.: Infra- Inzheneriya, 2010. - 432 p.

4 Скворцов В.П. О бурении на пермотриас и пермь в Эмбенском районе. Нефтяные месторождения Урало-Эмбенского района. - М.-Л., ОНТИНКТПСССР, 1933. [Skvortsov V.P. Drilling for Permian Triassic and Permian waters in the Embensky region. Oil fields of the Ural-Embensky region. - M.-L., ONTI NKTP USSR, 1933]

5 Надиров Н.К. Нефть и газ Казахстана. Алматы: «Гылым», 1995; 290 [Nadirov N.K. Neft I gaz Kazakhstana; Almaty: "Gylym", 1995; 290] 